\title{
AÇõES AFIRMATIVAS NA UNIVERSIDADE FEDERAL DO ACRE: ACOMPANHAMENTO PÓS LEI DE COTAS
}

\author{
Andrio Alves Gatinho (UFPA)* \\ https://orcid.org/0000-0002-5853-4908 \\ Delcele Mascarenhas Queiroz (UNEB)** \\ https://orcid.org/0000-0002-8328-7101
}

\section{RESUMO}

0 artigo reflete sobre a política de cotas nos cursos de graduação da Universidade Federal do Acre (UFAC), a partir do exame do desempenho dos estudantes negros, oriundos de escola pública, que ingressaram na Instituição. A pesquisa analisa dados do ingresso de estudantes cotistas negros nos anos de 2013 e 2014, através da reserva de vagas definida pela Lei no 12.711/2012. Traçamos o perfil desses estudantes e examinamos o desempenho dos que ingressaram por duas modalidades de concorrência: uma formada por PPI com renda de até 1,5 SM (PPI até 1,5 SM) e outra formada por PPI independente de renda (PPI Indep.), em 10 (dez) cursos da Universidade. Parte das informações analisadas foi disponibilizada pela Pró-Reitoria de Graduação da Universidade; trabalhamos ainda com dados coletados via Lei de Acesso à Informação, além de dados do Censo do IBGE de 2010 e do Censo do Ensino Superior do INEP de 2013. 0 trabalho está dividido em três partes. Na primeira fazemos uma breve apresentação da Universidade, no segundo momento fazemos uma discussão sobre o balanço da política de cotas e por último analisamos os dados disponíveis. Palavras-chave: Ação afirmativa. Cotas. Universidade Federal do Acre (UFAC).

\section{ABSTRACT}

\section{AFFIRMATIVE ACTION AT THE FEDERAL UNIVERSITY OF ACRE: POST MONITORING QUOTA LAW}

The article reflects on the policy of quotas in undergraduate courses of the Federal University of Acre (UFAC), from examining the performance of black students coming from public schools, who entered the institution. The research analyzes the entry data of black students using racial quota in the years 2013 and 2014, through the reserved vacancies defined by Law 12,711/2012. We profile these students and examine the performance of those who joined by two

Doutor em Educação e Contemporaneidade pela Universidade do Estado da Bahia (Uneb). Professor da Universidade Federal do Pará (UFPA). E-mail: andriogatinho@gmail.com

** Doutora em Educação pela Universidade Federal da Bahia (UFBA). Professora da Universidade do Estado da Bahia (Uneb). E-mail: dmqueiroz@uol.com.br 
types of competition: one formed by PPI with incomes of up to $1.5 \mathrm{MW}$ (PPI up 1.5 MW) and another formed by PPI independent of income (PPI Indep.), within 10 (ten) University courses. Of the information analyzed it was released by the Pro-Rectory of Graduation; still we work with data collected via the Access to Information Act, and the 2010 IBGE Census data and the Higher Education Census INEP 2013. The work is divided into three parts. At first, we make a brief presentation of the University, the second part we make a discussion of the balance of the quota policy and finally we analyze the available data.

Keywords: Affirmative action. Quotas. Universidade Federal do Acre (UFAC).

\section{RESUMEN}

\section{ACCIONES AFIRMATIVAS EN LA UNIVERSIDAD FEDERAL DE ACRE: SEGUIMIENTO DESPUÉS DE LA LEY DE CUOTAS}

El artículo refleja sobre la política de cotas en los cursos de graduación de la Universidad Federal de Acre (UFAC), a partir del examen de desempeño de los estudiantes negros, oriundos de escuela pública, que ingresaron en la Institución. La pesquisa analiza datos del ingreso de estudiantes cotizantes negros en los años de 2013 y 2014, por medio de la reserva de plazas definida por la Ley 12.711/2012. Trazamos el perfil de estos estudiantes y analizamos el desempeño de los que ingresaron por dos modalidades de concurrencia: una formada por PPI con renta de hasta 1,5 SM (PPI hasta 1,5 SM) y otra formada por PPI independiente de renta (PPI Indep.), en 10 (Diez) cursos de la Universidad. Parte de las informaciones analizadas se ha obtenido de la Pro-Rectoría de Graduación de la Universidad; trabajamos aun con datos colectados de la Ley de Acceso a la Información, también de datos del Censo del IBGE 2010 y del Censo de la Enseñanza Superior del INEP 2013. El trabajo está dividido en tres partes. En la primera hicimos una breve presentación de la Universidad, en el segundo momento discutimos sobre el balance de la política de cotas y, por fin, analizamos los datos disponibles.

Palabras clave: Acción afirmativa. Cuotas. Universidade Federal do Acre (UFAC).

\section{UFAC e às ações afirmativas}

A Universidade Federal do Acre (UFAC) tem 51 anos, possui dois campus instituídos (Campus Sede - Rio Branco e Campus Floresta - Cruzeiro do Sul) e um em fase de implementação (Campus Fronteira - Brasiléia, reconhecido pelo Ministério da Educação em dezembro de 2014); oferta atualmente 44 cursos regulares, sendo 21 cursos de licenciatura e 23 cursos de bacharelado, com 34 oferecidos no Campus Sede e 10 oferecidos no Campus Floresta. Com base em números do primeiro semestre de 2014 (UNIVERSIDADE FEDERAL DO ACRE, 2015b), a Universidade possuía 8.132 alunos na Graduação. Enquanto processo seletivo, a UFAC, em 2010, aderiu parcialmente ao Exame Nacional do Ensino Médio (Enem) como processo de seleção para ingresso nos cursos de Licenciatura em Filosofia e em Música e para as vagas remanescentes do Edital Vestibular 2011. Posteriormente, em 2011, realizou a adesão integral ao Enem.

Trabalhamos neste texto com dados disponibilizados pela Pró-Reitoria de Graduação da Universidade (UNIVERSIDADE FEDERAL DO 
ACRE, 2015a), ${ }^{1}$ que nos concedeu o acesso ao Banco de Dados do Sistema de Seleção Unificada (Sisugestão), além de dados coletados via Lei de Acesso à Informação (BRASIL, 2015) junto à Secretaria de Ensino Superior (SESU) do Ministério da Educação (MEC), de dados do Censo 2010 do Instituto Brasileiro de Geografia e Estatística (2014) e do Censo do Ensino Superior 2013, realizado anualmente pelo Instituto Nacional de Estudos e Pesquisas Educacionais Anísio Teixeira (2014).

$\mathrm{Na}$ ausência de trabalhos que analisem a presença de negros (pretos e pardos) na UFAC, começamos a nos questionar sobre os efeitos em termos de acesso de estudantes negros nos cursos de alta seletividade e prestígio dessa instituição pós-lei de cotas. Segundo Santos (2013, p. 9-10), a Lei no 12.711 "uniformizou decisões variadas em mais de cinquenta instituições federais que, desde 2004, adotaram sistemas de cotas para estudantes oriundos do sistema público de ensino, negros e indígenas". ${ }^{2}$

Vale a pena considerar, para o acompanhamento progressivo da implementação da política, quem são esses atores? Quais mudanças trazem para a Universidade? Quais os interesses deles durante a formação? Eles são do Acre? Houve algum tipo de migração para ocupar essas vagas? Se houve, quais foram os cursos que mais receberam esses alunos? Quais as médias desses candidatos em comparação a outras modalidades de concorrência? Não conseguiremos responder todas essas perguntas, mas iniciamos uma série de reflexões sobre o perfil dos cotistas, a partir da análise dos dados relativos ao ingresso, com o intuito de refletir sobre a implementação do novo sistema de ingresso na UFAC.

Com relação à implementação de ações afirmativas, a UFAC vinha de uma curta trajetória de debates e pressões. Essa trajetória foi bem diferente das relatadas em publicação orga-

1 Agradecemos à Pró-Reitoria de Graduação da UFAC pelo pronto atendimento a nossa solicitação de acesso ao banco de dados do SISU.

2 A respeito dos estudantes indígenas, em razão do baixo número de estudantes regularmente matriculados não trataremos neste texto deste grupo. nizada por Jocélio Teles Santos (2012), sobre os processos de decisão das Universidades Públicas em relação à adoção de cotas. Nas trajetórias das 11 instituições analisadas na publicação, pesou para aprovação de cotas, entre outros fatores, a pressão do movimento negro, posição da administração superior, apoio à discussão pela categoria docente, professores com atividades pró-cotas, além de outros elementos contextuais que representaram a singularidade de cada uma das instituições. Para esse autor, a grande maioria das universidades adotou "modelos próprios com objetivos similares, [demonstrando] sistemas multifacetados com o objetivo de garantir a inclusão de populações e grupos, até então, sub-representados, principalmente nos cursos de prestígio e forte concorrência" (SANTOS, J., 2012, p. 12). Na UFAC isso foi diferente, pois não ganham destaque na Instituição essas diferentes pressões, ou tomando de empréstimo uma expressão de Jocélio Santos (2012), na Universidade o debate sobre cotas não mexeu com as estruturas de poder da instituição, ${ }^{3}$ nem se mostrou como um desafio de refletir sobre as próprias desigualdades nela presentes.

A adoção de cotas nas universidades públicas brasileiras foi um processo iniciado em 2002 e que levantou um conjunto de posições favoráveis ou não dentro do espaço acadêmico e em geral na sociedade brasileira. 0 debate feito durante os 10 primeiros anos de adoção de cotas, segundo o autor, foi o da manifestação de um discurso opinativo que reproduzia o que ainda ocorre em vários espaços da sociedade brasileira, especialmente direcionado à adoção de ações afirmativas para a população negra (SANTOS, J., 2012).

Com relação à implementação de ações afirmativas desenvolvidas na Instituição, uma delas foi o curso de Formação Docente Indígena, no Campus Floresta, no âmbito do Prolind, ${ }^{4}$

3 Existiram manifestações isoladas de docentes em apoio à politica de cotas, além de algumas posições apresentadas por membros do CONSU.

4 O Prolind é um programa de apoio à formação superior de professores que atuam em escolas indígenas de educação básica. São projetos de curso na área das Licenciaturas 
executado entre os anos de 2008-2012. Destacam-se dissertações de mestrado no Programa de Pós-Graduação em Letras: Linguagem e Identidade, além de um Colóquio Internacional "As Amazônias, as Áfricas e as Áfricas na Pan-Amazônia", realizado no mesmo programa em que a questão racial e a presença negra no estado foram objeto de reflexão.

Outra ação foi o debate sobre a implementação do ensino de história e cultura afro-brasileira e africana nos cursos de graduação da Instituição, entre os anos de 2009 e 2012, que resultou de mobilização interna de professores e da pressão do Fórum Estadual de Implementação da Lei no 10.639/2003. Nessa direção, inicialmente, se instituiu a disciplina de História da Arte Negra no curso de Licenciatura em Artes Cênicas; posteriormente, o curso de Licenciatura em História se mobilizou para tornar obrigatória a disciplina História da África. Por último, foi aprovada no âmbito do Centro de Educação, Letras e Artes uma disciplina a ser ofertada para os cursos de Licenciatura que procurou dar conta das determinações do ensino de história e cultura afro-brasileira, africana e indígena. Existem relatos isolados de ações de professores incluindo em suas aulas, e práticas, ações com a finalidade de preparar os professores para a reeducação das relações étnico-raciais. Somam-se também as ações do Programa Conexão de Saberes, as ações de formação continuada, como cursos de extensão, cursos de pós-graduação latu sensu em parceria com o programa Uniafro, que por discutir ações de combate ao racismo nas escolas e indicar alternativas para o ensino de história e cultura afro-brasileira e africana propiciavam, mesmo que isoladamente, uma discussão sobre o que é promover a diversidade em espaços educativos, neste caso no ensino superior.

No âmbito do Fórum dos Cursos de Graduação no ano de 2010, um dos GTs instituí-

Interculturais em instituições de ensino superior públicas federais e estaduais. 0 objetivo é formar professores para a docência no ensino médio e nos anos finais do ensino fundamental das comunidades indígenas (MINISTÉRIO DA EDUCAÇÃO, 2015). dos discutiu propostas de ações afirmativas desenvolvidas em outras instituições a fim de apresentar ao Conselho Universitário uma proposta para a UFAC. Destacam-se dois seminários realizados em 2011/2012 que colocaram o tema em debate e propiciaram à comunidade acadêmica a comunicação de análises de experiências de outras instituições, além de permitir espaço para os movimentos sociais negros apresentarem suas propostas etc.

0 debate das cotas ganha força a partir da sanção da Lei no 12.711, em agosto de 2012, e sua imediata implementação nas Universidades Públicas Federais (BRASIL, 2012). Naquela altura o debate passa a integrar a pauta do Conselho Universitário, uma vez que era preciso determinar as condições de implementação da reserva de vagas. A Instituição optou por adotar a reserva de $25 \%$ das vagas para ingresso nos cursos de graduação em 2013, e na seleção seguinte, em 2014, passou a reservar $50 \%$ de suas vagas, tal como prescreve a Lei.

Parte da atitude reticente da Instituição em discutir a política de cotas devia-se ao fato de a universidade receber em seu interior boa parte de seus alunos provenientes das escolas públicas, o que, do seu ponto de vista, não justificava a adoção da reserva de vagas. A "democratização" do acesso a vagas destacada por representantes da instituição nunca foi demonstrada por renda ou por cor, além de que essas posições em nenhum momento questionavam a quantidade de brancos, pretos e pardos nos cursos da Universidade. Por outro lado, a Instituição se valia ainda do discurso de que seria uma imensa dificuldade determinar os beneficiários das cotas raciais; isto é, saber quem eram os negros (pretos e pardos). Para isso prevaleciam hipóteses como a "não existência de negros" no Acre, e a de que a quantidade de pardos que compunham o alunado da Universidade já seria suficiente para preencher a reserva determinada por lei.

A dificuldade em reconhecer a presença da população negra do estado é reforçada pela 
grande quantidade de pardos, quantificados pelo Censo do IBGE de 2010 em 66,28\% da população. Os demais são: brancos $23,85 \%$, pretos $5,79 \%$, indígenas $2,17 \%$ e amarelos $1,89 \%$. Ao somarmos os percentuais relativos a pretos e pardos teremos $72,07 \%$ de negros na população residente no estado, segundo os dados do Censo 2010 do IBGE (INSTITUTO BRASILEIRO DE GEOGRAFIA E ESTATÍSTICA, 2014). Vejamos, por exemplo, na Tabela 1, a distribuição percentual das pessoas no estado do Acre que frequentavam cursos superiores de graduação. Os argumentos contra as cotas se embasavam em dados como estes.

Tabela 1 - Percentual de pessoas por cor/raça que frequentavam curso superior de Graduação

\begin{tabular}{|l|c|}
\hline \multicolumn{1}{|c|}{ COR/RAÇA } & ACRE \\
\hline Brancos & 30,94 \\
\hline Pretos & 3,71 \\
\hline Pardos & 62,49 \\
\hline Indígenas & 0,93 \\
\hline Amarelos & 1,93 \\
\hline Total & 100,00 \\
\hline
\end{tabular}

Fonte: Instituto Brasileiro de Geografia e Estatística (2014).

De acordo com a Tabela 1, os pardos representavam $62,49 \%$ das pessoas que frequentavam curso superior de graduação, portanto, o maior percentual, frente aos 30,94\% de brancos. A distribuição desse universo pelas redes de ensino indica que $45,62 \%$ cursavam a rede pública e $54,38 \%$ a rede privada de ensino superior, o que nos leva a destacar que a maioria dos pardos estava em instituições privadas de ensino superior (INSTITUTO BRASILEIRO DE GEOGRAFIA E ESTATÍSTICA, 2014).

A Tabela 2 apresenta a distribuição racial da população de 10 anos ou mais, com ensino superior completo no Acre, de acordo com os dados do Censo de 2010. Percebemos que a participação de brancos com ensino superior completo é de 39,47\%, comparativamente já é maior que a taxa de frequência em 2010, de $30,94 \%$. Outro aspecto é que o percentual de pardos, de 54,94\%, com ensino superior completo é menor que a taxa de frequência em 2010 (INSTITUTO BRASILEIRO DE GEOGRAFIA E ESTATÍSTICA, 2014). Chama atenção, nas Tabelas 1 e 2, o baixo índice de pretos tanto em relação à frequência quanto à conclusão do Ensino Superior em 2010.

Tabela 2 - Percentual de pessoas de 10 anos ou mais, por cor/raça com ensino superior completo

\begin{tabular}{|l|c|}
\hline \multicolumn{1}{|c|}{ COR / RAÇA } & ACRE \\
\hline Brancos & 39,47 \\
\hline Pretos & 3,98 \\
\hline Pardos & 54,94 \\
\hline Indígenas & 0,23 \\
\hline Amarelos & 1,38 \\
\hline Total & 100 \\
\hline
\end{tabular}

Fonte: Instituto Brasileiro de Geografia e Estatística (2014).

Além dos dados recolhidos do Censo 2010 do IBGE, buscamos os dados do Censo do Ensino Superior, do qual destacamos que a quantidade de alunos brancos matriculados na Universidade representava $44,72 \%$ das matrículas no ensino superior público no Acre, enquanto pardos, pretos e indígenas representavam, respectivamente, 3,19\%, 0,64\% e 0,09\% (INSTITUTO NACIONAL DE ESTUDOS E PESQUISAS EDUCACIONAIS ANÍSIO TEIXEIRA, 2013). Quase a metade das matrículas é ocupada por brancos na UFAC, única universidade pública do estado.

Como o Censo é respondido pela administração da Universidade, isso mostra a grande quantidade de alunos brancos identificados pela administração da Universidade na resposta ao Censo, o que não se aplica ao enorme índice de subnotificação quando direcionado a estudantes pretos e pardos. Existe, no caso do Censo do Ensino Superior ${ }^{5}$ de 2013, um elevado

5 Desde 2011, com taxas um pouco diferentes, o percentual 
percentual de "subnotificação", de 51,29\%, o qual consiste no somatório dos percentuais das respostas "Não dispõe da informação" e "Não declarado" ao Censo. 0 elevado percentual de matriculados que não dispõe da informação soma $44,36 \%$, além dos $6,93 \%$ que não declararam sua cor ou raça (INSTITUTO NACIONAL DE ESTUDOS E PESQUISAS EDUCACIONAIS ANÍSIO TEIXEIRA, 2013).

A subnotificação não é uma particularidade local, vez que no Censo do Ensino Superior é a maior entre todos os instrumentos de identificação racial utilizados nas diferentes políticas empreendidas pelo Governo Federal (SECRETARIA DE POLÍTICAS DE PROMOÇÃO DA IGUALDADE RACIAL, 2015). Isso demonstra a dificuldade das Universidades Públicas: mesmo passados 13 anos de implementação das primeiras medidas de ações afirmativas, ainda não dispõem de mecanismos eficientes de coleta e sistematização de dados sobre seus alunos, além de campanhas de orientação sobre a identificação racial dos alunos. Como podemos conferir, a subnotificação no caso do Acre está concentrada no campo "Não dispõe da Informação", o que pode ser corrigido se a instituição se dedicar a coletar e sistematizar essas informações a respeito do ingresso e desempenho de seus alunos.

Isso nos leva a considerar que mesmo com as dificuldades da instituição em reconhecer por cor e raça seus alunos, quando estes são pretos e pardos, este mesmo fenômeno não acontece com os alunos brancos, que se autoidentificam como tais e contam com a identificação da instituição.

Quando comparamos os censos de 2000 e 2010, percebemos que os índices de conclusão do ensino superior, no Acre, elevaram-se para brancos, pretos e pardos, porém, a distância entre os brancos e os demais grupos ainda é bastante significativa, conforme vemos na Tabela 3.

de subnotificação é de mais de 50\%, conforme verificamos na análise.
Tabela 3 - Proporção percentual de pessoas por cor/raça com curso superior de graduação completo no Acre

\begin{tabular}{|l|c|c|}
\hline ENSINO SUPERIOR COMPLETO & 2000 & 2010 \\
\hline Brancos & 6,32 & 15,1 \\
\hline Pretos / Pardos & 2,67 & 7,22 \\
\hline
\end{tabular}

Fonte: Instituto Brasileiro de Geografia e Estatística (2014).

0 Censo de 2010 evidencia que, apesar de ter aumentado o índice de pretos e pardos com ensino superior completo no estado, eles continuam sub-representados com relação aos brancos. A pesquisa de Souza (2009, p. 103) já havia encontrado uma "distorção entre os percentuais dos estudantes da UFAC, admitidos em 2008, tanto em relação à distribuição racial da população em geral, quanto em relação à proporção das pessoas em condições de pleitear ingresso no ensino superior, no Acre". Em suas análises já se verificava uma sobrerrepresentação de brancos na participação nas vagas da UFAC.

A pesquisa de Souza (2009) sobre a presença das camadas populares no ensino superior público do Acre analisou a constituição das trajetórias escolares desenvolvidas por jovens provenientes desses setores sociais que ingressaram nos cursos mais seletivos e prestigiosos da UFAC. Esta pesquisa apontou a estratificação social do acesso ao ensino superior público no Acre, evidenciando que no vestibular de 2008, mesmo que 60\% das vagas do Campus de Rio Branco dessa Universidade tenham sido ocupadas por jovens provenientes dos meios populares, isso não refletia uma maior democratização educacional.

Uma vez comparados os dados da pesquisa com os da estratificação social do Acre, "constata-se que a vantagem, no acesso a essa universidade, é dos jovens provenientes das camadas médias e superiores da sociedade" (SOUZA, 2009, p. 187); além de uma 
"expressiva divisão interna” entre os cursos e expectativas de carreira, a qual reflete o acesso às oportunidades educacionais em uma sociedade socialmente desigual. Segundo os resultados da pesquisa, mesmo que os estudantes provenientes dos meios populares acreanos ocupem a maioria das vagas, "eles parecem destinados às vagas rejeitadas pelos estudantes oriundos das camadas sociais superiores" (SOUZA, 2009, p. 188).

Segundo essa pesquisa, nos dois cursos de maior prestígio acadêmico e social oferecidos pela universidade (Direito e Medicina) a presença de estudantes provenientes de "famílias fracas detentoras de capital cultural e escolar" foi de $20 \%$ e 7,5\% respectivamente. Sugere a autora "uma clara hierarquização do campo acadêmico da UFAC" (SOUZA, 2009), que refletiria as diferenças sociais existentes na sociedade, corroborando a tese dos "excluídos do interior" (BOURDIEU, 1998), ou seja, da existência de formas mais ou menos brandas, mais ou menos dissimuladas de exclusão. Com efeito, o ingresso nos cursos mais seletos dessa universidade pública é estatisticamente improvável para os jovens dos meios populares (SOUZA, 2009).

Portes (2006, p. 227) nos diz que "se a condição econômica não é determinante das ações e práticas do estudante pobre, ela é um componente real, atuante, mobilizador de sentimentos que comumente produzem sofrimento neste tipo de estudante e ameaçam sua permanência na instituição". Para esse autor, manter um estudante nos cursos de alto prestígio, mesmo numa universidade pública, "são atos que retiram a tranquilidade da família, pois, trata-se de um ensino que, mesmo sendo público, é economicamente dispendioso. Exigências próprias do acadêmico e exigências características de cada curso exercem aí uma forte influência" (PORTES, 2006, p. 229).

Esses dados corroboram para o amadurecimento das questões em relação aos efeitos das políticas de cotas na UFAC, especialmente nos cursos altamente seletivos. Um primeiro passo foi dado, mesmo que tenha sido levado a cabo por força da lei. Precisamos entender em que medida a política de cotas está beneficiando pretos e pardos diferencialmente, e nesses grupos identificá-los por sexo, idade, desempenho na seleção etc. Devemos acompanhar o progresso desses estudantes na vida acadêmica a fim de compreender quais fatores podem comprometer a permanência dos estudantes negros nos cursos da Universidade.

\section{Política de cotas no Brasil}

Pesquisas como as de Queiroz (2004) revelaram a existência em um importante espaço no sistema de ensino brasileiro das desiguais condições de acesso entre os segmentos raciais. Por mais que a Universidade Federal da Bahia (UFBA), analisada na pesquisa por Queiroz, não dispusesse de mecanismos formais de discriminação racial, esta Instituição revelou-se um território de predomínio de brancos e morenos. Analisando separadamente as carreiras e sua composição racial no universo da pesquisa, Queiroz (2004) chega à conclusão que a distribuição racial obedecia a uma gradação de prestigio e cor em que a cor mais clara é identificada com as carreiras de mais elevado prestigio e a cor mais escura com aquelas de baixo prestígio. Ficou evidenciado, portanto, que os brancos estavam em cursos de maior prestígio, como Medicina, Direito, Engenharia, enquanto a inserção de negros se dava predominantemente em cursos de menor valorização, como os de licenciatura, cuja consequência é o ingresso no mercado de trabalho em espaços ocupacionais de menor importância e de salários pouco atraentes, renovando-se, assim, o ciclo da reprodução das desigualdades. Esses dados indicavam a urgência na adoção de medidas que ampliassem a participação de estudantes negros nos espaços valorizados do ensino superior, onde sua presença era bastante rarefeita (QUEIROZ, 2004). 
Esses dados demonstraram a composição racial dos estudantes que se encontravam nas universidades federais brasileiras e foram descritos como

[...] espaços predominantemente brancos, aos quais tem acesso estudantes oriundos de escolas privadas, que puderam manter-se afastados do mercado de trabalho durante a escolarização básica, cujos pais têm, em geral, elevada escolaridade, ocupação compatível com seu nível de instrução e renda familiar acima de seis salários mínimos. (QUEIROZ, 2009, p. 181).

Entre 2001 e 2012, com a implantação de políticas afirmativas para negros em diferentes universidades no Brasil, acompanhamos uma enxurrada de críticas e o acirramento das posições na discussão do tema do acesso dos negros ao ensino superior. Para Queiroz (2012), não se tem notícia, no país, de uma mobilização de tal magnitude, e partindo de atores tão qualificados, no debate denominado pelos críticos de "a guerra das cotas". Este acirramento demonstrava o alto grau de mobilização que se criou em torno da questão e passava pelos seguintes argumentos: a inconstitucionalidade da medida, o receio de uma racialização das relações sociais no Brasil, as desigualdades entre brancos e negros como decorrência da condição de pobreza a que estão submetidos esses grupos, a qualidade do ensino nas universidades medidas pelo "mérito acadêmico" e o ataque às políticas específicas.

Diferentemente das críticas postas às ações reparatórias, Queiroz e Santos (2006, 2007) apontam que políticas de ações afirmativas precisam de um acompanhamento sistemático do desempenho dos estudantes beneficiados para responder às críticas feitas à adoção de ações afirmativas, as quais, segundo seus propagandeadores, resultariam na baixa qualidade do ensino nas universidades medidas pelo "mérito acadêmico". Esse argumento ainda expressa a preocupação de que ingressariam estudantes sem o devido "preparo", o que ameaçaria a excelência do ensino universitário. Os pesquisadores dão conta de que não exis- tem grandes diferenças e apontam uma certa equivalência entre cotistas e não cotistas. Ao contrário da expectativa daqueles que se mostravam resistentes à implantação do sistema de cotas, e que temiam uma desqualificação do ensino pelo ingresso de estudantes, supostamente, despreparados na UFBA, o desempenho dos estudantes revela resultados bastante animadores, nos cursos das diversas áreas de conhecimento. Em 61\% dos cursos de maior concorrência, os cotistas obtiveram coeficiente de rendimento igual ou melhor que os não cotistas na análise de dois semestres cursados em 2005 (QUEIROZ; SANTOS, 2007).

Foram demonstradas, a partir de diferentes análises, como as da elevação do ponto de corte das notas do vestibular, o bom rendimento dos estudantes cotistas, a análise de situações de jubilamento e a eliminação do curso por faltas, as provas do êxito das políticas afirmativas nas universidades brasileiras, contrariando previsões de críticos do sistema de cotas, no sentido de que este provocaria uma queda no padrão acadêmico da universidade. Os dados confirmam a hipótese do bom desempenho de estudantes negros oriundos da escola pública, apontados por Queiroz (2004) como uma demanda reprimida de estudantes pretos e pardos que tiveram bom desempenho no vestibular e que eram aprovados, porém não classificados nas vagas.

Cordeiro (2013), em análise sobre os resultados da política de cotas na Universidade Estadual de Mato Grosso do Sul (UEMS), nos diz que independente dos índices de matrículas, evasão e conclusão de cursos, estes resultados devem ser vistos como positivos, considerando toda a trajetória dos estudantes cotistas. Para essa autora, não podemos esquecer que esta trajetória "é marcada pelas dificuldades de permanência, mobilizadas por vulnerabilidades financeiras e sociais, além das dificuldades e discriminações sofridas no espaço acadêmico, principalmente na sala de aula e nas relações que envolvem o processo de ensino e aprendizagem" (CORDEIRO, 2013, p. 34). 
Feres Junior, Campos e Daflon (2014), em análise sobre os dados do SISU de 2014, indicam ser muito pequena a diferença, se não insignificante, entre as notas de corte de cotistas e não cotistas. Ressaltam esses autores que o funcionamento do SISU criou incentivos para que a escolha de um curso superior se torne cada vez mais racional e estratégica, e que os candidatos modelem suas expectativas de carreira conforme o seu desempenho no Enem.

Os dados do SISU discutidos pelos autores indicam que os temores em relação ao desempenho dos cotistas no Enem são superestimados. 0 desempenho dos cotistas é, de modo geral, próximo do desempenho dos não cotistas e variam de acordo com os diferentes grupos beneficiados pelas cotas. Segundo esses autores, embora pequenas, essas diferenças de desempenho indicam que as cotas para egressos de escola pública que são pretos, pardos ou indígenas e/ou possuem baixa renda são mais necessárias e prementes que as cotas para egressos de escola pública, independentemente da cor ou renda. Esse dado sugere que cotas apenas para oriundos de escolas públicas não seriam suficientes para beneficiar estudantes pretos, pardos e indígenas e/ou de baixa renda, ao contrário do que costuma ser dito no debate público. Embora grande parte dos brasileiros não brancos e pobres esteja no ensino público, o pertencimento à escola pública não funciona como um proxy, isto é, não é suficiente para contemplar os primeiros (FERES JÚNIOR; CAMPOS; DAFLON, 2014).

Para esses autores, outro dado que chama atenção é o modo uniforme como cotistas se distanciam de não cotistas em termos de desempenho. Uma hipótese explicativa para isso pode ser encontrada no próprio funcionamento do SISU, que permite que os candidatos adéquem de modo mais racional sua aspiração por determinados cursos ao seu desempenho efetivo no Enem. Como efeito aparentemente não intencional, o sistema de apostas e rodadas adotado pelo SISU contribuiu para que cotistas maximizassem suas escolhas em função de suas notas (FERES JÚNIOR; CAMPOS; DAFLON, 2014).

Uma das características do SISU é a de realizar rodadas de distribuição de vagas ao longo de uma semana em que fica aberto às inscrições. Ao fim de cada dia, o candidato fica sabendo se sua nota está dentro da nota de corte do curso pretendido e com isso pode se movimentar a fim de obter o melhor proveito ou melhor adequar suas expectativas às suas notas.

Para Feres Junior, Campos e Daflon (2014), com esse movimento as notas entre os não cotistas e os diferentes tipos de cotistas tendem a se aproximar, uma vez que a informação da nota de corte, diariamente informada ao final de cada rodada, permite não somente que ele compare sua nota, mas também se informe acerca do nível da concorrência para todos os cursos. Se a nota obtida por ele estiver muito aquém da nota de corte do curso desejado na primeira rodada, o candidato pode mudar de opção nas rodadas posteriores e, assim, reduzir o risco de ficar de fora da universidade (FERES JÚNIOR; CAMPOS; DAFLON, 2014).

\section{Análise sobre os dados}

A seleção dos cursos a serem analisados levou em consideração aqueles com notas de corte mais elevadas, tanto dos cotistas PPI quanto dos não cotistas, ou seja, dos estudantes que disputaram pela Ampla Concorrência. Esse critério elencou uma relação de cursos que coincide, em parte, com aqueles que a pesquisa de Souza (2009), na UFAC, classificou como cursos "seletos" e "intermediários": Medicina e Direito - considerados pelo autor como "seletos" -, Engenharia Civil, Sistemas de Informação, Comunicação Social, Enfermagem - considerados na pesquisa citada como "intermediários". A esses adicionamos três outros cursos criados entre 2008 e 2011: Nutrição, Medicina Veterinária e Engenharia Elétrica, 
atendendo ao critério anteriormente descrito. Como critério de representatividade para atender os dois campi da Universidade, escolhemos do Campus Floresta o curso de Enfermagem. Como destacado por Santos e Queiroz (2013), os maiores impactos das políticas afirmativas foram nos cursos de maior concorrência e considerados de mais prestígio, o que justifica nossa escolha.

Os dez cursos selecionados representam, respectivamente, nas seleções de 2013 e 2014, em percentuais, $22,38 \%$ e $23,9 \%$ das vagas oferecidas, com 450 e 490 vagas ofertadas em números absolutos. Representaram 40,5\% e
$45,66 \%$ da quantidade de inscritos nas respectivas seleções, o que indica a relevância e prestigio social, com um total de 24.650 e 35.875 candidatos inscritos. A pesquisa de Queiroz (2004) indicava que é pelas carreiras de alto prestígio que se encontrava a disputa mais acirrada, porque são essas que conferiam maiores vantagens, tanto no mercado de trabalho quanto como elemento de distinção social.

Na Tabela 4 apresentamos a distribuição percentual entre os candidatos cotistas e não cotistas inscritos nos dez cursos selecionados, segundo a categoria de concorrência.

Tabela 4 - Distribuição percentual dos estudantes inscritos, nos dez cursos selecionados segundo o grupo de concorrência

\begin{tabular}{|l|c|c|}
\hline \multicolumn{1}{|c|}{ GRUPO DE CONCORRÊNCIA } & 2013 & 2014 \\
\hline Não Cotistas & 72,66 & 57,44 \\
\hline Cotistas & 25,65 & 41,5 \\
\hline $\begin{array}{l}\text { Ação Afirmativa para Candidatos com } \\
\text { Deficiência (AFCD) }\end{array}$ & 1,68 & 1,05 \\
\hline Total & 100,0 & 100,0 \\
\hline
\end{tabular}

Fonte: Universidade Federal do Acre (2015a).

De acordo com os dados da Tabela 4, os candidatos da ampla concorrência, isto é, não cotistas, são maioria tanto em 2013 como em 2014. Em 2013, a diferença entre não cotistas e cotistas foi de 47 pontos percentuais; em 2014, a distância entre os dois grupos se reduz para $15,94 \%$.

É possível pensar que essa diferença em favor dos candidatos não cotistas se deve, por um lado, ao sentimento de confiança dos candidatos da ampla concorrência que tradicionalmente ocuparam essas vagas, por terem recebido melhor formação nas escolas em que estudaram, em sua grande maioria da rede privada, e que viam como um caminho natural a ocupação deste espaço. Por outro lado, se pode atribuir a mais tímida participação dos não cotistas, à desconfiança na própria formação e ao medo do enfrentamento em um espaço que não é visto como legítimo para eles. A timidez dos estudantes cotistas que sabem que vão entrar em um lugar de forte concorrência, pode gerar autoexclusão, o que já foi encontrado em trabalho anterior. 0 processo de desqualificação a que está sujeito o negro concorre para afastá-lo da competição pelo acesso à universidade, por levá-lo a não se reconhecer com legitimidade para concorrer a um espaço que tem sido, historicamente, um reduto das elites (QUEIROZ, 2004).

Essa variação pode ser explicada também pelo aumento da reserva de vagas, já que na seleção de 2013 a UFAC reservou apenas 25\% de suas vagas aos cotistas, e no ano seguinte passou a oferecer $50 \%$ de vagas, conforme determina a Lei no 12.711 (BRASIL, 2012). 
Tabela 5 - Distribuição dos estudantes inscritos na modalidade PPI com renda até 1,5 SM, segundo o curso, em 2013 e 2014

\begin{tabular}{|c|c|c|c|}
\hline \multicolumn{2}{|c|}{2013} & \multicolumn{2}{c|}{2014} \\
\hline Curso & Quant. & Curso & Quant. \\
\hline Medicina & 929 & Medicina & 3.301 \\
\hline Direito & 570 & Direito & 936 \\
\hline Nutrição & 305 & Nutrição & 701 \\
\hline Enfermagem & 302 & Enfermagem & 684 \\
\hline Eng. Civil & 285 & Eng. Civil & 586 \\
\hline Med. Veterinária & 267 & Med. Veterinária & 382 \\
\hline Com. Social & 197 & Com. Social & 450 \\
\hline Eng. Elétrica & 144 & Eng. Elétrica & 270 \\
\hline Sistemas & 140 & Sistemas & 319 \\
\hline Enfermagem CZS & 54 & Enfermagem CZS & 288 \\
\hline Total & 3.193 & Total & 7.917 \\
\hline
\end{tabular}

Fonte: Universidade Federal do Acre (2015a).

Em cinco dos cursos selecionados para análise (Nutrição, Enfermagem, Engenharia Civil, Comunicação Social, Sistemas), percebe-se uma elevação na procura dos candidatos PPI até 1,5 SM de mais de $100 \%$, entre 2013 e 2014 . Os cursos de Direito, Medicina Veterinária e Engenharia Elétrica tiveram aumento um pouco menor. 0 curso de Enfermagem CZS (Campus Floresta) e o curso de Medicina foram os que registraram os maiores aumentos, de $433 \%$ e $255 \%$, respectivamente.

Dispomos de informações gerais que o sistema nos permitiu colher, mas algumas informações que julgamos essenciais, como, por exemplo, quanto ao nível de renda, escolaridade dos pais, se era a primeira seleção que eles estavam prestando ou a quantas seleções eles estavam tentando ingressar na Universidade, não sabemos, vez que a base de dados do SISU não dispõe dessa informação. ${ }^{6}$

\subsection{Ingresso por gênero}

Tabela 6 - Distribuição percentual por gênero e por ano nos cursos selecionados

\begin{tabular}{|l|c|c|}
\hline & 2013 & 2014 \\
\hline Homens & 51,14 & 57,14 \\
\hline Mulheres & 48,86 & 42,86 \\
\hline Total & 100,00 & 100,00 \\
\hline
\end{tabular}

Fonte: Universidade Federal do Acre (2015a).

O ingresso nos 10 cursos em 2013 e 2014 foi de $51,14 \%$ e $57,14 \%$ de homens, respectivamente, e de $48,86 \%$ e $42,86 \%$ de mulheres,

6 É na inscrição do Enem que os candidatos preenchem um questionário socioeconômico. 
respectivamente, nos mesmos anos. Isso indica certo equilíbrio na seleção de 2013 e o aumento da presença masculina em 2014.

De acordo com os dados do Censo do Ensino Superior 2013 (INSTITUTO NACIONAL DE ESTUDOS E PESQUISAS EDUCACIONAIS ANÍSIO TEIXEIRA, 2014), os homens representavam $50,2 \%$ e as mulheres $49,8 \%$ no total de ingressos em todos os cursos de Bacharelado na Universidade Federal do Acre, resultado similar ao encontrado na análise dos 10 cursos no ano de 2013. No mesmo Censo, invertiam-se as posições de homens e mulheres quando analisadas as matrículas por sexo naquele ano. As mulheres representavam $50,77 \%$ das matrículas, enquanto os homens representavam $49,23 \%$.

Tabela 7 - Distribuição percentual de pessoas que frequentavam curso de superior de Graduação por gênero no Acre e no Brasil

\begin{tabular}{|l|c|c|}
\hline & BRASIL & ACRE \\
\hline Homens & 43,05 & 39,29 \\
\hline Mulheres & 56,95 & 60,71 \\
\hline Total & 100,00 & 100,00 \\
\hline
\end{tabular}

Fonte: Instituto Brasileiro de Geografia e Estatística (2014).

De acordo com a Tabela 7, no Acre, as mulheres frequentam mais o ensino de Graduação $(60,71 \%)$ do que a média nacional, que é de 56,95\%, segundo o Censo de 2010. Contudo, a frequência mais elevada das mulheres não reper- cute nos cursos de alto prestígio da UFAC, como vimos anteriormente, nos anos analisados. Os dados indicam que elas são minoritárias nos cursos mais valorizados, sendo maioria apenas nos cursos tradicionalmente ocupado por mulheres.

Tabela 8 - Percentual de pessoas com ensino médio completo e superior incompleto por cor/raça e gênero no Acre

\begin{tabular}{|l|c|c|c|c|}
\hline \multirow{2}{*}{\multicolumn{1}{|c|}{ Cor/Raça }} & \multicolumn{2}{|c|}{2000} & \multicolumn{2}{c|}{2010} \\
\cline { 2 - 5 } & Homens & Mulheres & Homens & Mulheres \\
\hline Brancos & 16,4 & 18,7 & 23,4 & 27,5 \\
\hline Pretos/pardos & 10,3 & 13,4 & 19,9 & 24,1 \\
\hline Total & 26,7 & 32,1 & 43,3 & 51,6 \\
\hline
\end{tabular}

Fonte: Instituto Brasileiro de Geografia e Estatística (2014).

As Tabelas 8 e 9 mostram as desigualdades existentes entre homens brancos e negros e as diferenças de mulheres brancas e negras. De acordo com a Tabela 8, a diferença entre homens e mulheres brancas ou pretas e pardas é significativa entre os que tem concluído o Ensino Médio e conseguiram ingressar no Ensino Superior. Entre os homens, em uma década, a distância entre brancos e pretos e pardos diminuiu de 6,1 para 3,5, e entre as mulheres, de 5,3 caiu para 3,4 . Percebemos que, mesmo com a queda na diferença, ainda se mantém uma diferença entre brancos e negros no Acre, o que se torna mais acentuada haja vista a diferença populacional entre brancos e pretos e pardos ser grande no conjunto da população. 
Tabela 9 - Proporção de pessoas com ensino superior completo por cor/ raça e gênero no Acre

\begin{tabular}{|l|c|c|c|c|}
\hline \multirow{2}{*}{\multicolumn{1}{c|}{ Cor/Raça }} & \multicolumn{2}{c|}{2000} & \multicolumn{2}{c|}{2010} \\
\cline { 2 - 5 } & Homens & Mulheres & Homens & Mulheres \\
\hline Brancos & 6,30 & 6,35 & 12,40 & 17,60 \\
\hline Pretos / Pardos & 2,39 & 2,97 & 5,58 & 8,88 \\
\hline Total & 8,69 & 9,32 & 17,98 & 26,48 \\
\hline
\end{tabular}

Fonte: Instituto Brasileiro de Geografia e Estatística (2014).

Na Tabela 9 fica evidente o sucesso no crescimento de homens e mulheres pretos e pardos em uma década no Acre, mas quando comparados aos dados de homens e mulheres brancos, mais uma vez fica claro o distanciamento entre os grupos.

Se na Tabela 8 percebemos que a diferença é de 3,4 entre as mulheres brancas e negras na conclusão do ensino médio e no ingresso ao ensino superior, situação diferente encontramos com os 8,72 pontos que as separam na conclusão do grau de ensino superior.

Queiroz (2008) destaca que diferentes análises sobre a participação por gênero no sistema de ensino têm confirmado a presença expressiva da mulher nos níveis básicos da escolarização, superando, inclusive, a participação masculina e mostrado a elevação da sua presença no ensino superior. Por exemplo, as mulheres no Acre frequentam mais a escola no total da população residente e só é apresentada uma pequena diferença quando destacada a situação do domicílio, onde elas são em número inferior na zona rural. Ou seja, elas estudam mais, concluem o ensino médio em maior número, entram no ensino superior em maior número, mas não ingressam nos cursos de alto prestígio na mesma proporção, como vimos anteriormente. Outro aspecto é que, proporcionalmente, as mulheres pretas e pardas são significativamente em maior número na população, mas não no ingresso e conclusão do ensino superior nos cursos de alto prestigio. Portanto, existe um mecanismo de impedimento de mulheres negras nos cursos de mais prestígio no Acre, o que esperamos que a política de cotas ajude a corrigir ao longo do tempo.

Na pesquisa de Carlinda Santos (2012) sobre a política de cotas na UFBA, buscando detectar a presença de mulheres negras em cursos de alto prestígio social, são eloquentes os depoimentos dessas estudantes ao relatarem experiências de racismo e de sexismo vivenciadas no seu cotidiano da Universidade. Ao referir-se à relação professor(a)/aluno(a), por exemplo, mostram as entrevistadas que essa relação pode representar uma barreira para estudantes de determinado meio social ou de determinado segmento racial. Em geral, os professores tomam como referência, na sua prática, os estudantes oriundos de um meio social mais próximo do seu, ignorando ou desdenhando dos estudantes que vêm de outro universo social, e que trazem certas dificuldades inerentes a uma educação em condições menos favoráveis, ou que dispõem de certos modos diferentes dos seus.

Também a dissertação de Jesus (2015), sobre professoras negras ex-cotistas da UFBA, fornece elementos importantes para compreender tanto o cotidiano universitário de dificuldades vivenciado por elas quando estudantes, quanto a determinação com que se aferram à oportunidade trazida pela política de cotas para a superação das suas condições de existência. 
Para Queiroz (2008), o desempenho feminino evidenciou ainda que as mulheres estão superando o padrão de socialização que as mantinha atreladas àquelas atividades profissionais mais assemelhadas ao mundo privado, rompendo, ao mesmo tempo, o bloqueio a sua presença nos espaços que, ao longo do tempo, estiveram reservados aos homens. Apesar da sua reduzida presença, destacou-se o desempenho das mulheres mulatas e pretas em cursos de elevado prestígio social, o que aponta uma tendência à mudança na representação que relaciona as mulheres pretas e mulatas às ocupações menos valorizadas do mercado de trabalho.

Tabela 10 - Distribuição percentual dos candidatos aprovados por gênero por curso nos anos de 2013 e 2014

\begin{tabular}{|l|c|c|c|}
\hline \multicolumn{1}{|c|}{ CURSO } & Homens & Mulheres & Total \\
\hline Medicina & 61,86 & 38,14 & 100,00 \\
\hline Direito & 67,64 & 32,36 & 100,00 \\
\hline Nutrição & 23,52 & 76,48 & 100,00 \\
\hline Enfermagem & 28,81 & 71,19 & 100,00 \\
\hline Engenharia Civil & 60,63 & 39,37 & 100,00 \\
\hline Medicina Veterinária & 36,73 & 63,26 & 100,00 \\
\hline Comunicação Social & 46,93 & 53,07 & 100,00 \\
\hline Engenharia Elétrica & 78,21 & 21,79 & 100,00 \\
\hline Sistemas de Informações & 85,26 & 14,74 & 100,00 \\
\hline Enfermagem CZS & 33,33 & 66,67 & 100,00 \\
\hline
\end{tabular}

Fonte: Universidade Federal do Acre (2015a).

De acordo com a Tabela 10, percebemos que somente no curso de Comunicação Social a distribuição de homens e mulheres é mais equilibrada, com uma leve vantagem para as mulheres. Os homens são majoritários nos cursos de Medicina, Direito, Engenharia Civil, Engenharia Elétrica e Sistemas de Informação; nos demais, é das mulheres a participação mais expressiva. As carreiras com maioria de mulheres são nos cursos de Nutrição, os dois cursos de Enfermagem, Medicina Veterinária e Comunicação Social.

Queiroz (2001), examinando as razões apresentadas pelos estudantes para suas escolhas das carreiras, sinaliza para uma tendência de as mulheres fazerem sua opção pela carreira com base nos estereótipos de gênero, confirmando o que mostra a maioria dos estudos. Assim, é possível pensar que são justamente esses estereótipos que se revelam nas escolhas femininas sob a forma das "aptidões" e "interesses", razões mais apontadas por todos os estudantes, mas sobretudo pelas mulheres. Segundo essa autora, ainda que não existam impedimentos formais ao acesso das mulheres ao ensino superior, o condicionamento social que orienta as suas escolhas tende a dirigi-las para as carreiras tradicionalmente "femininas". Para Queiroz (2001), haveria uma tendência do grupo feminino para "escolher" cursos impregnados de conteúdo humanístico e que desembocam, imediata ou posteriormente, em profissões tradicionalmente desempenhadas por mulheres, a exemplo de magistério, artes e enfermagem. 0 trabalho indica que a manutenção da tendência de "escolha", pelas mulheres, das carreiras "femininas" é um fenômeno que traz como consequência a manutenção da 
estratificação por gênero e atua no sentido de reduzir o efeito democratizador do acesso das mulheres ao ensino universitário (QUEIROZ, 2008).
Ao trazer para comparação os dados do Censo 2010 nas carreiras selecionadas para esta pesquisa, segundo o gênero, temos a distribuição apresentada na Tabela 11.

Tabela 11 - Distribuição percentual por gênero e carreiras

\begin{tabular}{|l|c|c|c|c|}
\hline \multicolumn{1}{|c|}{ Carreiras } & $\begin{array}{c}\text { Homens } \\
\text { Brasil }\end{array}$ & $\begin{array}{c}\text { Homens } \\
\text { Acre }\end{array}$ & $\begin{array}{c}\text { Mulheres } \\
\text { Brasil }\end{array}$ & $\begin{array}{c}\text { Mulheres } \\
\text { Acre }\end{array}$ \\
\hline Jornalismo e Informação & 36,77 & 44,61 & 63,23 & 55,39 \\
\hline Direito & 53,90 & 56,64 & 46,10 & 43,36 \\
\hline Computação & 73,36 & 75,94 & 26,64 & 24,06 \\
\hline Engenharias e profissões correlatas & 84,76 & 82,95 & 15,24 & 17,05 \\
\hline Veterinária & 54,96 & 59,31 & 45,04 & 40,68 \\
\hline Saúde & 34,19 & 36,30 & 65,81 & 63,70 \\
\hline
\end{tabular}

Fonte: Instituto Brasileiro de Geografia e Estatística (2014).

A comparação entre os dados da UFAC e os dados do Censo 2010 confirma os estudos sobre o tema, como vimos anteriormente, acerca da participação de homens e mulheres nos cursos: as carreiras das Engenharias e da Computação são tradicionalmente ocupadas por homens, e na UFAC isso não é diferente, como evidencia a Tabela 10. Conforme a Tabela 10, a participação dos homens é de 78,21\% e $60,63 \%$, respectivamente, em Engenharia Elétrica e Civil, e no curso de Sistemas de Informação os homens representam 85,26\%, o que demarca a maioria absoluta de homens nesses cursos na UFAC.

Embora as mulheres sejam, frequentemente, majoritárias nos cursos da área de saúde, o curso de Medicina da UFAC tem em sua composição a maioria masculina, com $61,86 \%$. Sendo o curso mais tradicional e concorrido da Instituição, é um espaço disputados pelos homens, que percebem aí a possibilidade de obtenção e/ou manutenção de privilégios.

Diante do quadro de distribuição por gênero, cabia o questionamento se as mesmas diferenças eram encontradas separando os dois grandes grupos de concorrência: cotistas e não cotistas. A Tabela 12 a seguir mostra a comparação.

Tabela 12 - Distribuição percentual por gênero por grupo de concorrência nos anos de 2013 e 2014

\begin{tabular}{|l|c|c|}
\hline & Não cotistas & Cotistas \\
\hline Homens & 52,14 & 57,06 \\
\hline Mulheres & 47,86 & 42,94 \\
\hline Total & 100,00 & 100,00 \\
\hline
\end{tabular}

Fonte: Universidade Federal do Acre (2015a).

Com base na leitura da Tabela 12, percebemos que os homens são maioria nos dois principais grupos de concorrência. Entre os candidatos da "ampla concorrência", a diferença entre homens e mulheres é um pouco menor, sugerindo, provavelmente, que no segundo grupo as mulheres estão em condições menos favoráveis, seja do ponto de vista socioeconômico, seja do ponto de vista das representações de gênero.

Vejamos agora apenas os cotistas PPI, que são o maior contingente entre os cotistas. Os homens são maioria, nas duas modalidades de concorrência, e com quase a mesma participação, conforme a Tabela 13 a seguir. 
Tabela 13 - Distribuição percentual dos estudantes PPI, por gênero nos anos de 2013 e 2014

\begin{tabular}{|l|c|c|c|}
\hline Modalidades de Concorrência & Homens & Mulheres & Total \\
\hline PPI até 1,5 SM & $59,06 \%$ & $40,94 \%$ & 100,00 \\
\hline PPI Independente de renda & $59,57 \%$ & $40,43 \%$ & 100,00 \\
\hline
\end{tabular}

Fonte: Universidade Federal do Acre (2015a).

A comparação realizada por Queiroz (2008), na UFBA, entre o momento da implantação da reserva de vagas (2005) e o momento imediatamente anterior (2004), no que tange à participação das mulheres, demonstrou que as mulheres pardas foram o contingente que mais se beneficiou dessa política. A análise evidenciou que a política de cotas permitiu um maior acesso das mulheres negras aos cursos oferecidos pela UFBA, mesmo naquele grupo de cursos considerados de maior prestígio social. As mulheres autodeclaradas pretas ainda têm uma presença bastante reduzida nos cursos desse nível de prestígio (QUEIROZ, 2008).

Na Tabela 14 a seguir, apresentamos a distribuição percentual de candidatos PPI com renda até $1,5 \mathrm{SM}$, por curso, segundo o gênero.

Tabela 14 - Distribuição percentual de candidatos "PPI até 1,5 SM" por curso, segundo o gênero nos anos de 2013 e 2014

\begin{tabular}{|l|c|c|c|}
\hline \multicolumn{1}{|c|}{ Cursos } & Homens & Mulheres & Total \\
\hline Medicina & 80,95 & 19,05 & 100,00 \\
\hline Direito & 75,00 & 25,00 & 100,00 \\
\hline Enfermagem & 33,33 & 66,67 & 100,00 \\
\hline Engenharia Civil & 60,00 & 40,00 & 100,00 \\
\hline Nutrição & 33,33 & 66,67 & 100,00 \\
\hline Medicina Veterinária & 28,57 & 71,43 & 100,00 \\
\hline Eng. Elétrica & 75,00 & 25,00 & 100,00 \\
\hline Sistemas de Informações & 80,00 & 20,00 & 100,00 \\
\hline Comunicação. Social & 56,25 & 43,75 & 100,00 \\
\hline Enfermagem CZS & 44,44 & 55,56 & 100,00 \\
\hline
\end{tabular}

Fonte: Universidade Federal do Acre (2015a).

Percebe-se que as diferenças entre homens e mulheres se acentuam quando colocamos em perspectiva candidatos pretos e pardos de renda baixa. Enquanto a participação das mulheres na UFAC, no curso de Medicina, no período investigado, é de $38,14 \%$ (como apresentado na Tabela 9), observando-se essa participação no grupo de cotistas percebe-se a posição mais desfavorável das mulheres aí, representando apenas 19,05\%, o que aponta para a desvantagem das pretas e pardas. Além do curso de Medicina, também no curso de Direito acontece fenômeno similar, com a diminuição na proporção de mulheres pretas e pardas. Curiosamente, no curso de Engenharia Civil é quase igual a proporção encontrada de homens e mulheres entre os candidatos "PPI até 1,5 SM". Isso ocorre também quando se observa todo o conjunto dos aprovados, independentemente da categoria de concorrência. 
Outra evidência curiosa é que nos cursos de Engenharia Elétrica e Sistemas de Informação a proporção de mulheres pretas e pardas é mais elevada que para o conjunto dos estudantes.

Nas carreiras com maioria de mulheres, Nutrição e Enfermagem, as pretas e pardas continuam com a maioria das vagas, porém em menor proporção que no conjunto dos aprovados(as). No curso de Medicina Veterinária as mulheres pretas e pardas são, proporcio- nalmente, mais presentes. Ao contrário, no curso de Comunicação Social as selecionadas pretas e pardas são minoritárias, confirmando a participação das mulheres no conjunto das aprovadas para esse curso.

Isso evidencia que as cotas não atingem as mulheres pretas e pardas da mesma forma, principalmente quando colocamos em perspectiva as mulheres pretas e pardas com renda de até $1,5 \mathrm{SM}$.

Tabela 15 - Distribuição percentual de candidatos "PPI Indep. de renda" por curso, segundo o gênero nos anos de 2013 e 2014

\begin{tabular}{|l|c|c|c|}
\hline \multicolumn{1}{|c|}{ Cursos } & Homens & Mulheres & Total \\
\hline Medicina & 47,05 & 52,95 & 100,00 \\
\hline Direito & 71,42 & 28,58 & 100,00 \\
\hline Enfermagem & 22,22 & 77,78 & 100,00 \\
\hline Eng. Civil & 66,66 & 33,34 & 100,00 \\
\hline Nutrição & 42,85 & 57,15 & 100,00 \\
\hline Medicina Veterinária & 60,00 & 40,00 & 100,00 \\
\hline Engenharia Elétrica & 75,00 & 25,00 & 100,00 \\
\hline Sistemas de Informações & 88,88 & 11,12 & 100,00 \\
\hline Comunicação Social & 61,53 & 38,47 & 100,00 \\
\hline Enfermagem CZS & 30,00 & 70,00 & 100,00 \\
\hline
\end{tabular}

Fonte: Universidade Federal do Acre (2015a).

Uma situação diferente da encontrada na Tabela 14 é a das mulheres cotistas pretas e pardas sem a limitação da renda. No curso de Medicina, por exemplo, as mulheres pretas e pardas, independentemente de renda, representam 52,95\% dos candidatos selecionados, bem diferente dos 19,05\% de mulheres pretas e pardas com renda de "até 1,5 SM". Isso demonstra o quão significativo é a renda no acesso de mulheres pretas e pardas ao ensino superior.

\subsection{Notas de corte}

Tabela 16 - Média das notas dos candidatos por grupo de concorrência referente à primeira chamada do SISU

\begin{tabular}{|l|c|c|}
\hline Grupos de concorrência & 2013 & 2014 \\
\hline Não Cotistas & 672,34 & 665,39 \\
\hline Cotistas & 655,24 & 633,67 \\
\hline
\end{tabular}

Fonte: Universidade Federal do Acre (2015a). 
Na primeira chamada do SISU, as médias apresentadas pelos candidatos cotistas contrariam os discursos e as expectativas de parte da sociedade que se colocava contrária às cotas. 0 desempenho médio dos cotistas nas seleções de 2013 e 2014 nos cursos analisados se mostrou bem próximo dos candidatos não cotistas, variando entre 2,54\% em 2013 e 4,77\% em 2014. Em geral, as médias foram próximas, conforme demonstrado na Tabela 16.

Segundo o estudo de Feres Junior, Campos e Daflon (2014), no ano de 2014, a nota de corte média dos candidatos de ampla concorrência às Universidades e Institutos Federais (IFES) foi 661,63 , enquanto a nota de corte média dos cotistas egressos de escola pública foi de 645,22 , ou seja, uma diferença da ordem de $3 \%$. Ao desagregar os dados, separando as universidades federais e os institutos técnicos federais, esses autores encontraram que a nota de corte média dos candidatos da ampla concorrência nas universidades federais foi de 668,95, e de 651,82 dos cotistas egressos de escolas públicas; a nota de corte média dos cursos de institutos tecnológicos foi de 639,56 para ampla concorrência e de 625,32 para egressos de escola pública.

Outra constatação desses autores ocorre em relação à variação entre as modalidades de curso (bacharelado, licenciatura, tecnológico ou área básica); nesse aspecto é possível perceber que as notas de corte dos cursos de bacharelado tendem a ser superiores às outras modalidades, de modo mais ou menos uniforme. A distância entre os candidatos nessas modalidades parece ser igualmente uniforme, isto é, as diferenças de desempenho entre não cotistas e cotistas não varia substantivamente conforme a natureza do curso. 0 mesmo se aplica ao turno dos cursos (integral, matutino, noturno ou vespertino). Embora os ingressantes nos cursos integrais e matutinos tendam a ter notas mais elevadas que os noturnos ou vespertinos, a distância entre cotistas e não cotistas em cada uma dessas rubricas tende a ser uniforme. Logo, não é possível dizer que em cursos de uma ou outra natureza as diferenças entre cotistas e não cotistas cresce ou diminui (FERES JUNIOR; CAMPOS; DAFLON, 2014).

Esse foi um movimento visto também no curso de Medicina da UFAC, tradicionalmente o mais concorrido da Universidade, no qual mesmo com as notas de corte mais altas das seleções de 2013 e 2014 em todas as modalidades de concorrência, a diferença entre candidatos não cotistas e cotistas teve quase a mesma distância encontrada na média geral dos 10 cursos analisados.

Tabela 17 - Média das notas no curso de Medicina dos candidatos por grupo de concorrência referente à primeira chamada do SISU

\begin{tabular}{|l|c|c|}
\hline Grupos de Concorrência & 2013 & 2014 \\
\hline Não cotistas & 765,8 & 752,43 \\
\hline Cotistas & 736,63 & 714,19 \\
\hline
\end{tabular}

Fonte: Universidade Federal do Acre (2015a).

Mesmo com a alta seletividade presente no curso, embora o desempenho dos não cotistas continue um pouco acima, o desempenho dos cotistas chama atenção, mostrando que entre esses também encontram-se os de excepcional desempenho na disputa pela carreira mais prestigiada de toda a seleção. Em 2013, a diferença entre não cotistas e cotistas foi de 3,81\%, e de 5,08\% em 2014, o que é um resultado próximo ao do conjunto dos estudantes.

No trabalho de Feres Junior, Campos e Daflon (2014) é possível observar que as diferenças de desempenho entre os não cotistas costumam ser maiores que as diferenças de desempenho entre não cotistas e cotistas. No entanto, para esses autores, é preciso considerar que na maior parte dos cursos considerados a diferença de pontuação entre cotistas e não cotistas é da ordem de 10 a 20 pontos, uma diferença pequena, segundo eles. Para eles, a distância é menor entre a nota de corte do cotista com pior desempenho relativo (o egresso de escola pública autodeclarado preto, pardo ou indígena e de baixa renda) e a do último colocado na 
ampla concorrência (FERES JUNIOR; CAMPOS; DAFLON, 2014).

Tabela 18 - Diferença percentual dos candidatos não cotistas aos cotistas por grupo de concorrência referente à primeira chamada do SISU

\begin{tabular}{|l|c|c|}
\hline \multicolumn{1}{|c|}{ Modalidade } & 2013 & 2014 \\
\hline PPI Até 1,5 SM & 5,15 & 6,72 \\
\hline PPI Independente de renda & 3,68 & 5,83 \\
\hline Demais até 1, 5 SM & 1,95 & 5,65 \\
\hline $\begin{array}{l}\text { Demais independente de } \\
\text { renda }\end{array}$ & 1,31 & 1,94 \\
\hline
\end{tabular}

Fonte: Universidade Federal do Acre (2015a).

Analisando a Tabela 18 é possível verificar que a diferença de pontuação entre cotistas e não cotistas variou entre 2013 e 2014 . Podemos perceber que a maior distância na média da pontuação de não cotistas e cotistas encontra-se entre os candidatos pretos, pardos e indígenas com renda de até 1,5 SM, o que indica que o critério racial e de renda tem aí um efeito, mesmo que seja pouco acentuado.

Feres Junior, Campos e Daflon (2014) chegam à conclusão de que as distâncias nas notas entre os cotistas e os não cotistas tende a aumentar com a combinação de variáveis, ou seja, candidatos que sofrem com as exclusões socioeconômicas, raciais e educacionais tendem a ter uma nota mais distante daqueles que concorrem pela ampla concorrência, mesmo que ela seja baixa. Em quase $40 \%$ dos cursos analisados por esses autores, os cotistas pretos, pardos e indígenas com renda de até 1,5 SM obtêm escores entre 30 e 50 pontos abaixo das notas dos não cotistas da ampla concorrência. Apesar disso, a distância entre o não cotista e esse cotista que experimenta múltiplas exclusões ainda é baixa, já que ele obtém uma nota apenas 6,77\% inferior à dos não cotistas.

Para esses autores, a variável raça é responsável por reduzir mais a média do que a variável renda, o que significa que candidatos que sofrem com as exclusões socioeconômicas, raciais e educacionais tendem a ter uma nota mais distante daqueles que concorrem pela ampla concorrência do que candidatos que experimentam apenas uma dessas exclusões (FERES JUNIOR; CAMPOS; DAFLON, 2014).

Em nossa pesquisa, os candidatos cotistas egressos de escola pública apresentaram uma distância, em média, de $2 \%$ em relação à média dos não cotistas. Essa distância é mais elevada para os candidatos egressos de escola pública com renda de até $1,5 \mathrm{SM}$, que no ano de 2014 foi de mais de $5 \%$. No trabalho de Feres Junior, Campos e Daflon (2014), a nota de corte dos egressos da escola pública (independentemente da cor e da renda) foi inferior à nota de corte da ampla concorrência em apenas $2,44 \%$. Segundo esses autores, o desempenho dos cotistas costuma ser bem próximo do desempenho dos não cotistas também quando se leva em conta os cursos de maior ou menor prestígio, ou seja, ele costuma acompanhar a competitividade de cada curso. Esta tendência é forte mesmo quando comparados os candidatos da ampla concorrência e os cotistas mais "defasados".

Tabela 19 - Diferença percentual entre candidatos não cotistas e cotistas por grupo de concorrência segundo o último candidato selecionado

\begin{tabular}{|l|c|c|}
\hline Modalidades de concorrência & 2013 & 2014 \\
\hline PPI até 1,5 SM & 12,82 & 3,85 \\
\hline PPI independente de renda & 1,52 & 5,81 \\
\hline
\end{tabular}

Fonte: Universidade Federal do Acre (2015a).

A Tabela 19 mostra a diferença entre candidatos não cotistas e candidatos cotistas PPI quando levamos em consideração os últimos candidatos selecionados em cada uma das modalidades de concorrência, nos anos de 2013 e 2014. Em 2013, na medida em que avançam as convocações, ${ }^{7}$ ou chamadas, dos candidatos para a ocupação das vagas, a diferença entre o último candidato não cotista e o último candidato cotista negro com renda até $1,5 \mathrm{SM}$ aumenta, chegando a $12,82 \%$ na última chamada.

7 A seleção de 2013 contou com dezesseis chamadas para ocupar todas as vagas ofertadas. 
No ano de $2014^{8}$ a distância entre candidatos PPI com renda até 1,5 SM e os candidatos da ampla concorrência na última chamada diminui para 3,85\%, bem abaixo dos $6,72 \%$ da primeira chamada. Em relação aos candidatos PPI independente de renda, a distância permanece praticamente a mesma entre a média dos candidatos nas convocações.

\section{Conclusões}

Este trabalho demonstra o primeiro movimento para se analisar a implementação da reserva de vagas para negros na Universidade Federal do Acre. São evidentes os efeitos positivos da inclusão de jovens negros de camadas populares nos cursos de alto prestígio na Instituição nos primeiros anos de implementação das medidas. Ao contrário do que se imaginava, os escores de pontuação dos candidatos cotistas foram bem próximos dos candidatos não cotistas nos primeiros dois anos do cumprimento da Lei, o que se aproxima da média nacional do desempenho dos cotistas nas IFES encontrada por Feres Junior, Campos e Daflon (2014).

Outro efeito positivo que apontamos referese ao encorajamento de pretos e pardos pela disputa desse espaço tido, até aqui, como "inalcançável", demonstrado no aumento significativo da inscrição desse grupo de concorrentes para a seleção da UFAC.

As diferenças na ocupação das vagas dos cotistas PPI, entre homens e mulheres, demonstra que os homens têm ocupado em maior número essas vagas, indicando que as mulheres negras não têm se beneficiado da mesma forma da reserva de vagas. Chama atenção o fato de que as mulheres pardas no estado concluem em maior número o ensino médio e ingressam em maior quantidade no ensino superior, mas não ocupam as vagas nos cursos de alto prestígio.

É urgente a necessidade da identificação de cor/raça em todos os instrumentos internos dos estudantes da Instituição, em razão do alto percentual de estudantes que não têm sua

8 Doze chamadas foram realizadas. cor ou raça identificadas no Censo do Ensino Superior. A subnotificação dificulta a análise da implementação da política e inviabiliza a identificação dos principais obstáculos e fragilidades.

Como assinalou Queiroz (2013), a explicitação dos aspectos positivos da aplicação da política de cotas é importante, e não pode ser vista como otimismo acrítico. A divulgação dos dados sobre o bom desempenho dos cotistas é necessária, inclusive para combater a posição dos que buscam desqualificá-los e/ou invisibilizá-los. Numa sociedade em que a raça é estruturante das relações sociais, há que se estar constantemente alerta, vez que a atuação do racismo vai além das relações interpessoais; está incorporado ao próprio modo como operam as instituições.

\section{REFERÊNCIAS}

BRASIL. Governo Federal. Acesso à informação. Disponível em: http://www.acessoainformacao. gov.br/. Acesso em: maio 2015.

BRASIL. Presidência da República. Casa Civil. Lei no 12.711, de 29 de agosto de 2012. Dispõe sobre o ingresso nas universidades federais e nas instituições federais de ensino técnico de nível médio e dá outras providências. Brasília, DF, 2012. Disponível em: http://www.planalto.gov.br/ ccivil_03/_ato2011-2014/2012/lei/l12711.htm. Acesso em: jul. 2015.

BOURDIEU, P. Escritos de educação. Petrópolis. RJ: Vozes, 1998.

CORDEIRO, M. J. de J. A. Um balanço das cotas para negros e indígenas na Universidade Estadual de Mato Grosso do Sul: da criação das leis aos dias atuais, In: SANTOS, J. T. dos (org.). 0 impacto das cotas nas universidades brasileiras (20042012). Salvador, CEAO, 2013. p. 15-36.

FERES JUNIOR, J; CAMPOS, L. A; DAFLON, V. T. O desempenho dos cotistas no ENEM: comparando as notas de corte do SISU. Textos para discussão GEMAA. Rio de Janeiro, n. 4, p. 2-23, 2014. Disponível em: http://gemaa.iesp.uerj.br/. Acesso em: maio 2015.

INSTITUTO BRASILEIRO DE GEOGRAFIA E ESTATÍSTICA (IBGE). Censo Demográfico 2010. 
Brasília, DF, 2014. Disponível em: http://censo2010. ibge.gov.br/. Acesso em: jul. 2015.

INSTITUTO NACIONAL DE ESTUDOS E PESQUISAS EDUCACIONAIS ANÍSIO TEIXEIRA (INEP). Censo da educação superior 2013 - resumo técnico. Brasília, DF: INEP, 2014. Disponível em http://portal.inep.gov.br/superior-censosuperiorsinopse. Acesso em: jul. 2015.

JESUS, C. C dos S. Professoras da educação básica egressas da política de cotas na UFBA: experiências formativas, percepções e práticas em torno das relações etnicorraciais. 2015, 140 f. Dissertação (Mestrado em Educação e Contemporaneidade) - Departamento de Educação da Universidade do Estado da Bahia (UNEB), Salvador, 2015.

MINISTÉRIO DA EDUCAÇÃO (MEC). Prolind. Disponível em: http://portal.mec.gov.br/prolind. Acesso em: 15 maio 2015.

PORTES, E. A. Algumas dimensões culturais da trajetória de estudantes pobres no ensino superior público: o caso da UFMG. Revista Brasileira de Estudos Pedagógicos, Brasília, DF, v. 87, n. 216, p. 220-235, maio/ago. 2006.

QUEIROZ, D. M. 0 acesso ao ensino superior: gênero e raça. Caderno CRH, Salvador, n. 34, p. 175-197, jan./jun. 2001.

QUEIROZ, D. M. Universidade e desigualdade. Brancos e negros no ensino superior. Brasília, DF: Liber Livro, 2004.

QUEIROZ, D. M. Ações afirmativas na universidade brasileira e acesso de mulheres negras. Revista Ártemis, João Pessoa, v. 8, p. 132-145, jun. 2008.

QUEIROZ, D. M. Da invisibilidade ao centro do debate: o negro na universidade no século XXI. In: AMORIM, A.; LIMA JÚNIOR, A. S. de; MENEZES, J. M. de (org.). Educação e Contemporaneidade, Rio de Janeiro: Quartet, 2009. p. 169-202.

QUEIROZ, D. M. As políticas de cotas para negros nas universidades brasileiras e a posição dos intelectuais. Revista Pedagógica, Chapecó, SC, v. 1, n. 28, p. 355-376, jan./jun. 2012.

QUEIROZ, D. M. Ações afirmativas para negros na universidade pública brasileira: uma década depois. In: e-GEINCOS, 3., 2013, João Pessoa. Anais [...]. João Pessoa: Universidade Federal da Paraíba (UFPB), 2013.
QUEIROZ, D. M.; SANTOS, J. T. dos. Sistema de cotas: um debate. Dos dados à manutenção dos privilégios e do Poder. Educação e Sociedade, Campinas, SP, v. 27, n. 96, p. 717-737, out. 2006.

QUEIROZ, D. M.; SANTOS, J. T. dos. Sistema de cotas: um multiculturalismo brasileiro? Ciência e Cultura (SBPC), São Paulo, v. 59, n. 2, p. 41-45, 2007.

QUEIROZ, D. M.; SANTOS, J. T. dos. O impacto das cotas na Universidade Federal da Bahia (20042012). In: SANTOS, J. T. dos (org.). 0 impacto das cotas nas universidades brasileiras (20042012). Salvador, CEAO, 2013, p. 37-66.

SANTOS, C. M. A mulher negra no ensino superior: trajetórias e desafios. 2012, 156 f. Dissertação (Mestrado em Educação e Contemporaneidade) - Departamento de Educação da Universidade do Estado da Bahia (UNEB), Salvador, 2012.

SANTOS, J. T. dos (org.). Cotas nas universidades: análises dos processos de decisão. Salvador: CEAO, 2012.

SANTOS, J. T. dos (org.). 0 impacto das cotas nas universidades brasileiras (2004-2012). Salvador, CEAO, 2013.

SECRETARIA DE PROMOÇÃO DE POLÍTICAS DE IGUALDADE RACIAL (SEPPIR). Orientações para a qualificação do quesito cor ou raça no Censo do Ensino Superior. Brasília, DF: Secretaria de Promoção de Políticas de Igualdade Racial, 2015. Disponível em: http://www.seppir.gov.br. Acesso em: jul. 2016.

SOUZA, M. S. N. M. de. Do seringal à universidade: o acesso das camadas populares ao ensino superior público no Acre. 2009. 214f. Tese (Doutorado em Educação) - Faculdade de Educação da Universidade Federal de Minas Gerais (UFMG), Belo Horizonte, 2009.

UNIVERSIDADE FEDERAL DO ACRE (UFAC). Ingresso no Ensino Superior 2013 a 2014. SISUGESTÃo. Rio Branco, 2015a. Disponível em: http:// sisugestao.mec.gov.br/. Acesso em maio 2015.

UNIVERSIDADE FEDERAL DO ACRE (UFAC). UFAC em números. Rio Branco, 2015b. Disponível em: http://www.ufac.br/portal/home-ufac/ufac-emnumeros. Acesso em: jul. 2015.

Recebido em: 28/05/2019 Aprovado em: 02/07/2019 